Article

\title{
Analysis of Antimicrobial Use and the Presence of Antimicrobial-Resistant Bacteria on Austrian Dairy Farms- A Pilot Study
}

\author{
Clair L. Firth ${ }^{1, * \mathbb{D}}$, Annemarie Käsbohrer ${ }^{1}{ }^{\mathbb{D}}$, Peter Pless ${ }^{2}$, Sandra Koeberl-Jelovcan ${ }^{3}$ and Walter Obritzhauser ${ }^{1,4}$ \\ 1 Unit of Veterinary Public Health and Epidemiology, Institute of Food Safety, Food Technology \& Veterinary \\ Public Health, University of Veterinary Medicine, 1210 Vienna, Austria \\ 2 Veterinary Directorate and Administration, Styrian Provincial Government, 8010 Graz, Austria \\ 3 Institute for Medical Microbiology and Hygiene, Centre for Foodborne Infectious Diseases, Division for \\ Public Health, Austrian Agency for Health and Food Safety (AGES GmbH), 8010 Graz, Austria \\ 4 Veterinary Practice, 8605 Parschlug, Austria \\ * Correspondence: clair.firth@vetmeduni.ac.at
}

check for

updates

Citation: Firth, C.L.; Käsbohrer, A.;

Pless, P.; Koeberl-Jelovcan, S.;

Obritzhauser, W. Analysis of

Antimicrobial Use and the Presence

of Antimicrobial-Resistant Bacteria

on Austrian Dairy Farms-A Pilot

Study. Antibiotics 2022, 11, 124.

https://doi.org/10.3390/

antibiotics11020124

Academic Editors: Carlos M. Franco and David Rodríguez-Lázaro

Received: 23 December 2021

Accepted: 15 January 2022

Published: 18 January 2022

Publisher's Note: MDPI stays neutral with regard to jurisdictional claims in published maps and institutional affiliations.

Copyright: (c) 2022 by the authors. Licensee MDPI, Basel, Switzerland. This article is an open access article distributed under the terms and conditions of the Creative Commons Attribution (CC BY) license (https:/ / creativecommons.org/licenses/by/ $4.0 /)$.

\begin{abstract}
The assumed link between high levels of antimicrobial use on farms and selection for antimicrobial-resistant (AMR) bacteria on that farm remains difficult to prove. In the pilot study presented here, we analysed total antimicrobial use on 50 dairy farms in Austria and also collected environmental samples to ascertain whether specific AMR bacteria were present. Antimicrobial use (AMU) analysis was based on electronic veterinary treatment records over a one-year period. Faecal samples for the assessment of extended-spectrum beta-lactamase (ESBL)-producing E. coli were collected from cowsheds, calf pens, and youngstock housing areas, as well as dust samples from barns, to isolate methicillin-resistant Staphylococcus aureus (MRSA). Bacteriological cultures were carried out on selective agar. Farms were split into groups of 25 of the highest antimicrobial users and 25 of the lowest users. Overall, samples from $13 / 50$ (26.0\%) farms were found to be positive for the presence of ESBL-producing E. coli. Of these, eight farms were in the low user group and five were in the high user group. Only one farm was confirmed to harbour MRSA. Statistical analyses demonstrated that there was no significant difference in this study population between high or low antimicrobial use with respect to the presence of ESBL-producing E. coli on farms $(p=0.33)$. In conclusion, the presence of specific AMR bacteria on farms in this study population was not found to have a statistically proven relationship with their level of antimicrobial use.
\end{abstract}

Keywords: antimicrobial resistance; antibiotics; dairy; ESBL; MRSA; farms; veterinary

\section{Introduction}

Globally, the excessive use of antimicrobials and the increasing level of antimicrobialresistant bacterial infections in both humans and animals are continuing to cause concern among veterinarians, medics, and the general public [1]. Veterinary antimicrobial use worldwide is expected to increase by an estimated $11.5 \%$ by 2030 (based on 2017 figures), and so the problem will persist [2]. While many countries (such as China, Brazil, the USA, and Australia) continue to misuse antimicrobials for non-therapeutic growth promotion, such use has been banned in the European Union (EU) since 2006 [3,4]. In Austria, antimicrobials for use in animals are only available from veterinarians and never over the counter. Injectable antimicrobials are further restricted and can only be dispensed to farmers who are members of the Animal Health Service (Tiergesundheitsdienst) and have completed a specific training course in medication administration and documentation. Since 2015, all antimicrobials dispensed for use in food-producing animals by veterinarians must also be reported to the relevant authorities [5]. Based on the latest national reports (for 2020), the vast majority of dispensed antimicrobials (73.4\%) are provided for use in Austrian pig 
production, while $19.7 \%$ are for use in cattle (of which, around $7 \%$ are for dairy cows and $9 \%$ for beef cattle) and the remaining $6.7 \%$ for use in poultry [6].

Whilst a proven relationship between antimicrobial use (AMU) and the selection for antimicrobial-resistant (AMR) bacteria remains a contentious issue, a number of studies have assessed the possibility of such a correlation. In 2014, a report on seven European countries (including Austria) determined a strong association between total antimicrobial use in livestock in each country and the reported prevalence of AMR in E. coli in those countries [7]. Similarly, a study of outpatient antimicrobial consumption and AMR in human patients determined a strong linear relationship between macrolide use and resistant S. pneumoniae (MRSP) in 16 countries (including Austria) [8]. Meanwhile, a study from the Netherlands determined no association between total AMU on farms and the presence of ESBL/AmpC-producing E. coli, although a correlation between increasing third- and fourth-generation cephalosporin use and increasing levels of these cephalosporin-resistant bacteria was detected [9]. More recently, a Swedish study of antimicrobial use on dairy farms analysed the presence of resistant phenotypes among E. coli and found no link between overall AMU and E. coli resistance [10]. However, the study's authors noted that AMU in Sweden is generally much lower than in other EU countries [10].

With respect to the risk to humans from antimicrobial-resistant bacteria in food, a number of studies have found evidence of AMR bacteria [11-13], including an Austrian study in 2014 which reported the presence of ESBL-producing E. coli in 20\% of minced pork/beef samples tested, as well as MRSA in $9 \%$ of these samples [14]. As part of the EU AMR monitoring system, the European Food Standards Agency (EFSA) and the European Centre for Disease Control and Prevention (ECDC) publish joint annual summary reports on AMR in zoonotic and indicator bacteria from humans, animals, and food. The Austrian health authorities provide data for these reports and the most recent national monitoring results in 2019 reported the isolation of ESBL/AmpC-producing E. coli in 4 of $340(1.2 \%)$ beef samples, as well as MRSA in 6 of $228(2.8 \%)$ beef samples [15-17]. A recent panEuropean study of 11 countries, including Austria, failed to detect a statistically significant association between ESBL and/or AmpC-producing E. coli (i.e., those resistant to thirdgeneration cephalosporins) in humans and calves under one year of age [18]. Nevertheless, a source attribution model of ESBL-producing E. coli in the Netherlands highlighted that transmission to and from non-human sources (including cattle) is necessary to continue the intra-community spread of ESBL-producing E. coli and plasmid-mediated AmpCproducing E. coli [19].

The study presented here represents initial data from a pilot study of a small group of dairy farms, where extensive data on antimicrobial use over a one-year period, as well as farm management practices, were available. These data, as well as whether farms were considered "high" or "low" users of antimicrobials relative to the study population, were compared with the prevalence of ESBL-producing E. coli and MRSA obtained from samples collected on farms.

\section{Results}

In total, 138 voided faecal samples were collected from 50 farms (25 classified as "high" antimicrobial users and 25 as "low" users). Samples from the areas of the barn where cows were kept were available from all 50 farms. Calves were present on 46/50 farms $(92.0 \%)$ and pooled samples (1-5 animals per pool) were taken from calf holding areas/hutches. Youngstock (>six months of age) were present on $32 / 50$ farms $(64.0 \%)$ and pooled samples (1-5 animals per pool) were taken from their pens. An additional ten pooled samples were taken from calves and youngstock on four farms, which reared more than 50 head of cattle. Dust samples were taken from all 50 farms.

\subsection{Farm Population}

In the "high" AMU group, the mean herd size was 47.3 head of cattle (median 38; range 14-128), including 22.6 dairy cows (median 17; range 8-56); whereas in the "low" AMU 
group, the mean herd size was 57.1 head of cattle (median 52; range 11-157), including 29.6 dairy cows (median 24; range 5-77). In the high use group, $17 / 25(68.0 \%)$ farms were run conventionally, while just $2 / 25(8.0 \%)$ farms were organic producers. No production type was reported for the remaining six farms $(24.0 \%)$ as the farmers did not complete the farm management survey (as previously described elsewhere [20]). In the low use group, $7 / 25(28.0 \%)$ farms were run organically, $14 / 25$ (56.0\%) conventionally, and production type was not known for the remaining 4 farms. Of the 40 farmers in the overall study group who completed the farm management survey, $27(67.5 \%)$ reported that they routinely fed waste/discard milk containing antimicrobial residues (from the treatment of cows) to calves on their farms. For further details, see Table 1.

Table 1. Demographics of study farms, total AMU in DDDvet/cow/year, and results of ESBLproducing E. coli screening.

\begin{tabular}{|c|c|c|c|c|}
\hline DDDvet/Cow/Year & \multicolumn{2}{|c|}{ HIGH $(\mathrm{N}=25)$} & \multicolumn{2}{|c|}{ LOW $(N=25)$} \\
\hline Range & \multicolumn{2}{|c|}{$2.47-8.04$} & \multicolumn{2}{|c|}{$0.01-0.63$} \\
\hline Median & \multicolumn{2}{|c|}{3.82} & \multicolumn{2}{|c|}{0.31} \\
\hline \multirow[t]{2}{*}{ Mean } & \multicolumn{2}{|c|}{4.35} & \multicolumn{2}{|c|}{0.29} \\
\hline & Freestall $(n=17)$ & Tie-stall $(n=8)$ & Freestall $(n=16)$ & Tie-stall $(n=9)$ \\
\hline \multicolumn{5}{|l|}{ Production system } \\
\hline Conventional & 12 & 5 & 11 & 3 \\
\hline Organic & 2 & 0 & 5 & 2 \\
\hline No answer given $\#$ & 3 & 3 & 0 & 4 \\
\hline \multicolumn{5}{|l|}{$\begin{array}{l}\text { Waste milk * routinely fed to } \\
\text { calves }\end{array}$} \\
\hline Yes & 12 & 3 & 9 & 3 \\
\hline No & 2 & 2 & 7 & 2 \\
\hline No answer given ${ }^{\#}$ & 3 & 3 & 0 & 4 \\
\hline \multicolumn{5}{|l|}{$\begin{array}{l}\text { ESBL-producing } E \text {. coli present on } \\
\text { farm }\end{array}$} \\
\hline Cowshed boot swabs & 2 & 1 & 3 & 1 \\
\hline Calf samples & 3 & 1 & 5 & 2 \\
\hline Youngstock samples & 2 & 2 & 0 & 0 \\
\hline $\begin{array}{l}\text { Total number of farms with at least } \\
\text { one positive ESBL-producing } E \text {. } \\
\text { coli sample }\end{array}$ & 3 & 2 & 6 & 2 \\
\hline $\begin{array}{l}\text { Total number of farms where all } \\
\text { three samples were } \\
\text { ESBL-producing E. coli positive }\end{array}$ & 2 & 1 & 0 & 0 \\
\hline
\end{tabular}

* Waste milk is defined here as non-saleable milk, usually containing antimicrobial residues, or within the milk withholding period. \# Farmer did not complete farm management survey; therefore this information is not available for this farm.

\subsection{Bacteriology of Farm Samples}

ESBL-producing E. coli were isolated in faecal samples from 13 (26\%) of the 50 participating farms. Of these 11 pooled calf samples, seven pooled cowshed boot swab samples and four pooled youngstock samples were positive (for details, see Table 1). Three "high use" farms were found to be positive in all types of bovine faecal samples (i.e., cows, calves, and youngstock); while two of the "low use" farms were positive in both the cow and calf sample types and no youngstock were present at the time of sampling. One "high use" farm kept enough calves and youngstock ( $>5$ head in each group) to require two pooled samples to be taken; however, these additional samples were negative, as were the other samples from this farm. In total, additional pooled samples were taken from three "low use" farms with sufficient animals. On two of these farms, all samples were negative and on one farm, the samples from cows and calves were positive for ESBL-producing E. coli in both the standard and additional samples. 
Dust samples from only one farm were found to be positive for MRSA, this isolate was found to contain the mecC gene.

\subsection{Antimicrobial Use Data}

The total Defined Daily Doses per cow and year (DDDvet/cow/year) for all disease indications on each farm was calculated according to the standardised Defined Daily Dose (DDDvet) values published by the European Medicines Agency [21]. Total antimicrobial use (AMU) for all disease indications ranged from 2.47 to 8.04 DDDvet/cow/year in the high use group (mean 4.35; median 3.82 DDDvet/cow/year), compared to 0.01 to $0.63 \mathrm{DDDvet} / \mathrm{cow} /$ year in the low use group (mean 0.29; median 0.31 DDDvet/cow/year). As would be expected, the two groups ("high" and "low" AMU in DDDvet/cow/year) of antimicrobial use showed a highly statistically significant difference in the Mann-Whitney U-test (U score $0, \mathrm{Z}$ score $4.88, p<0.00001$ ).

Among high antimicrobial users on ESBL-producing E. coli positive farms, the median AMU was 3.38 DDDvet/cow/year (mean 3.77, $n=5$ ); compared to the negative farms where the median AMU was 4.14 DDDvet/cow/year (mean 4.50, $n=20$ ). On farms classed as low users, the median AMU was 0.40 DDDvet/cow/year (mean 0.31, $n=8$ ) on farms where at least one sample tested positive, compared to a median of $0.29 \mathrm{DDDvet} / \mathrm{cow} / \mathrm{year}$ (mean $0.28, n=17$ ) on negative farms.

The comparison of antimicrobial classes used on both ESBL-producing E. coli positive and negative farms is shown in Figure 1. On ESBL-producing E. coli positive farms, betalactamase sensitive penicillins (such as benzylpenicillin) had the highest DDDvet/cow /year (mean 0.49, median 0.12, maximum 1.95 DDD/cow/year); while the DDDvet/cow/year for third/fourth-generation cephalosporins was higher on the ESBL-producing E. coli-negative farms (mean 1.13, median 0.19, maximum 6.39 DDD/cow/year) (for details, see Figure 1). As would be expected on dairy farms, the majority of antimicrobial treatment on all farms was for udder diseases (53.8\% as calculated as a total of the DDDvet/cow/year), followed by a much lower proportion of treatments for reproductive disorders $(17.8 \%$ of the total DDDvet/cow/year) (for details, see Table 2 and Figure 2).

Table 2. Antimicrobial treatments by disease indication, according to DDDvet/cow/year, and whether farms tested positive or negative for ESBL-producing E. coli.

\begin{tabular}{|c|c|c|c|}
\hline & \multirow[t]{2}{*}{$\begin{array}{c}\text { Proportion of Overall } \\
\text { Antimicrobial Treatments (\%) } \\
\text { Based on Total } \\
\text { DDDvet/Cow/Year } \\
\end{array}$} & \multicolumn{2}{|c|}{$\begin{array}{l}\text { Proportion of Antimicrobial Treatments } \\
\text { by Disease Indication }\end{array}$} \\
\hline & & Non-HPCIA * & HPCIA * \\
\hline \multicolumn{4}{|l|}{ ESBL-POSITIVE FARMS (N = 13) } \\
\hline Respiratory disease & $13.2 \%$ & $54.8 \%$ & $45.2 \%$ \\
\hline Musculoskeletal/Locomotory disease & $5.2 \%$ & $32.5 \%$ & $67.5 \%$ \\
\hline Udder disease (excluding DCT \#) & $52.2 \%$ & $79.0 \%$ & $21.0 \%$ \\
\hline Reproductive disorders & $20.4 \%$ & $99.4 \%$ & $0.6 \%$ \\
\hline Other diseases & $9.0 \%$ & $47.8 \%$ & $52.2 \%$ \\
\hline \multicolumn{4}{|l|}{ ESBL-NEGATIVE FARMS (N = 37) } \\
\hline Respiratory disease & $12.4 \%$ & $78.1 \%$ & $21.9 \%$ \\
\hline Musculoskeletal/Locomotory disease & $8.4 \%$ & $10.6 \%$ & $89.4 \%$ \\
\hline Udder disease (excluding DCT ${ }^{\#}$ ) & $54.1 \%$ & $37.4 \%$ & $62.6 \%$ \\
\hline Reproductive disorders & $16.4 \%$ & $95.2 \%$ & $4.8 \%$ \\
\hline Other diseases & $8.6 \%$ & $45.4 \%$ & $54.6 \%$ \\
\hline
\end{tabular}

${ }^{*}$ HPCIA-highest priority critically important antimicrobials as defined by the World Health Organization [22]. For this study, HPCIA included third and fourth generation cephalosporins, macrolides, and fluoroquinolones. \# DCT-dry cow therapy. 


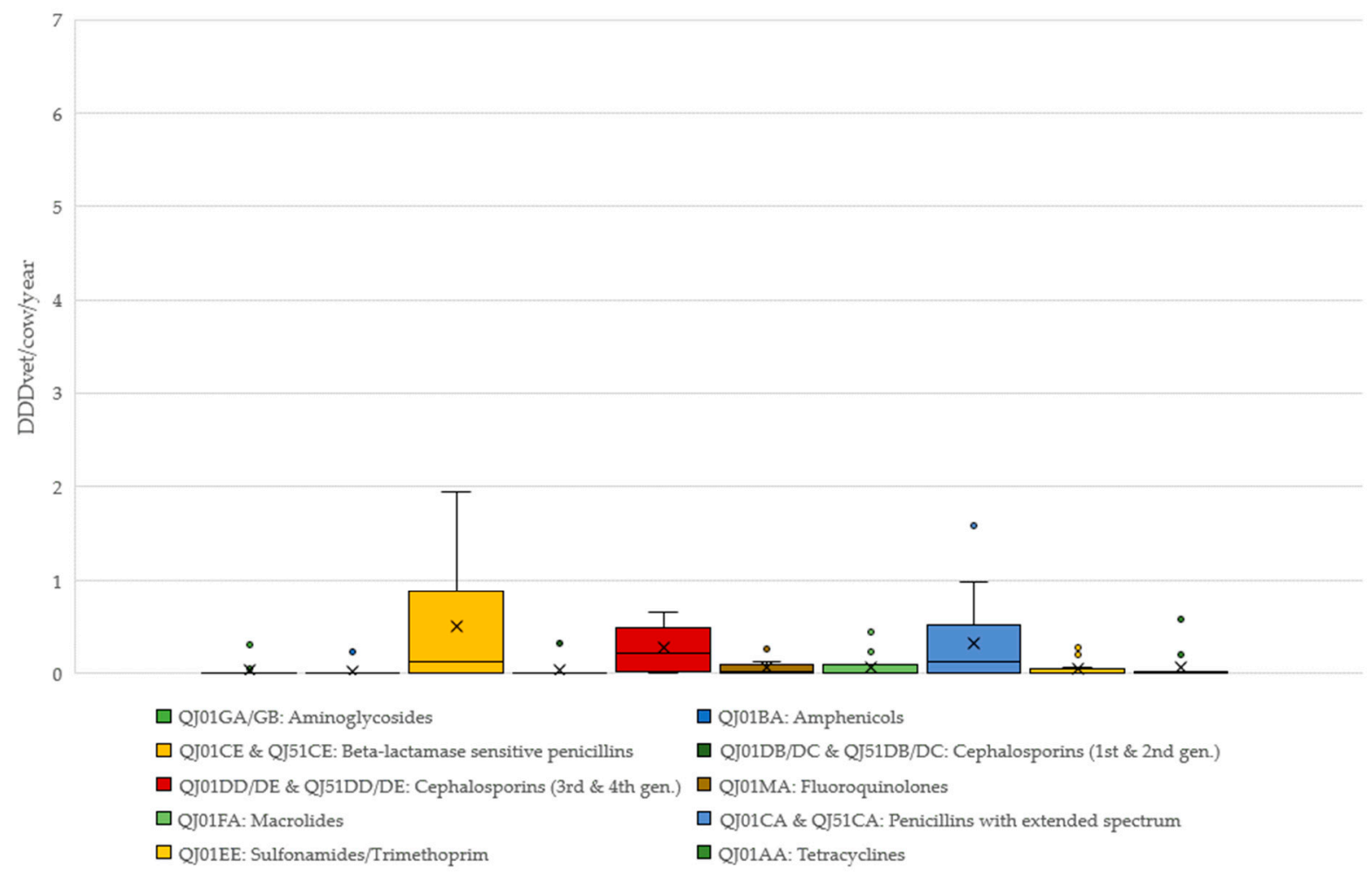

(A) ESBL-producing E.coli positive farms $(\mathrm{N}=13)$

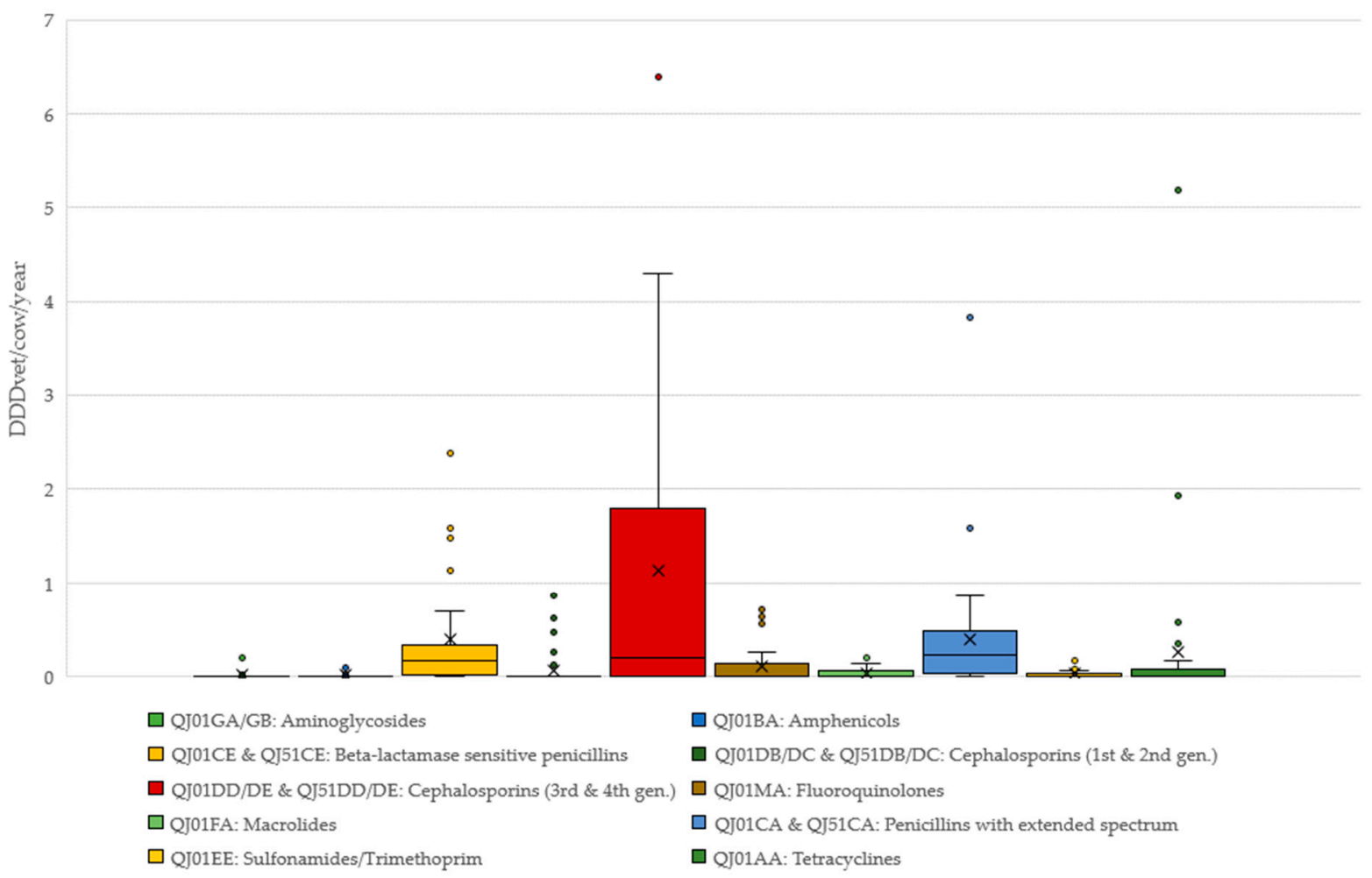

(B) ESBL-producing E.coli negative farms $(\mathrm{N}=37)$

Figure 1. Antimicrobial treatments by antimicrobial class (and ATCVet code), divided into those farms where faecal samples tested positive for ESBL-producing E. coli (A) and those where samples tested negative for ESBL-producing E. coli (B). 


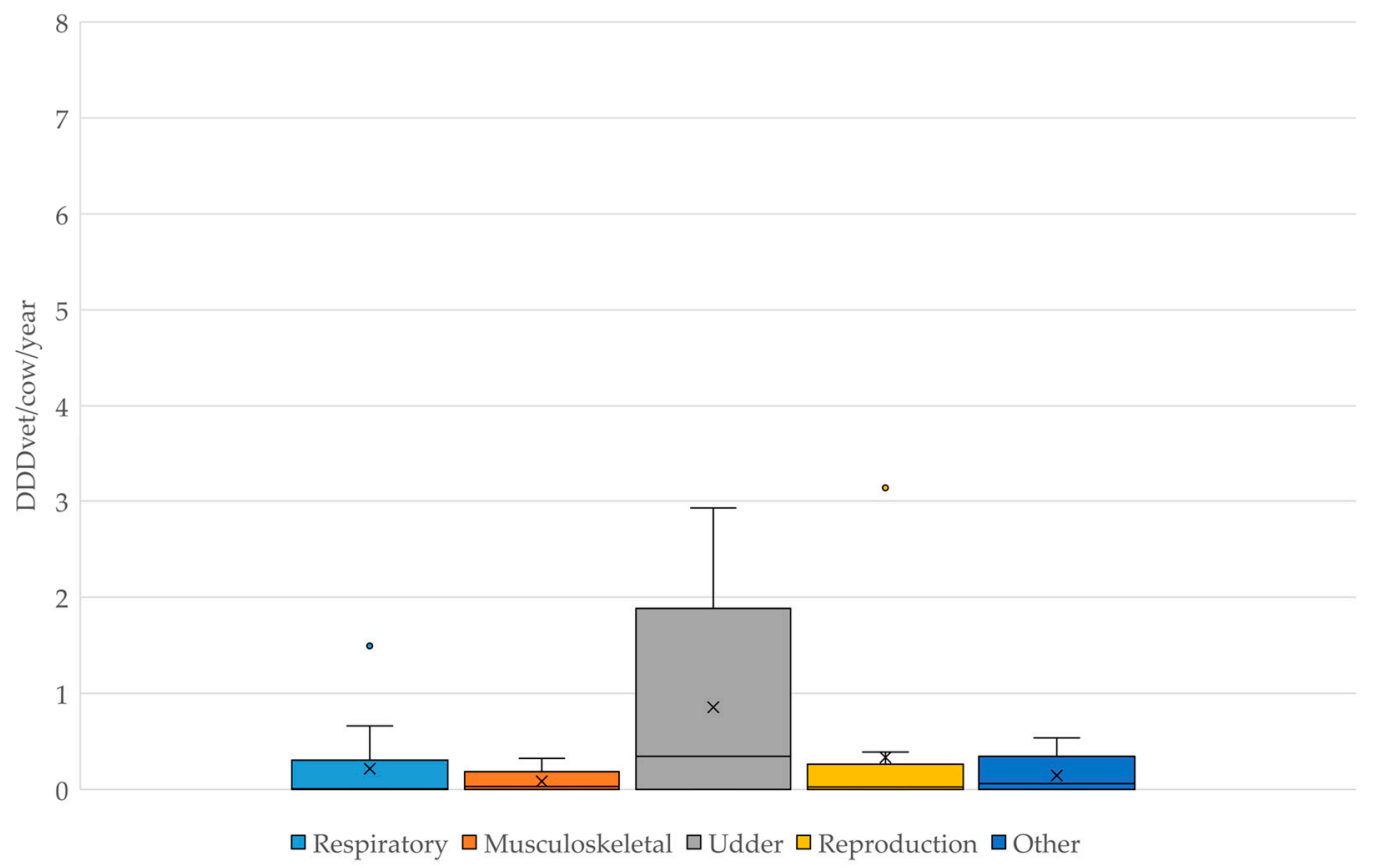

(A)

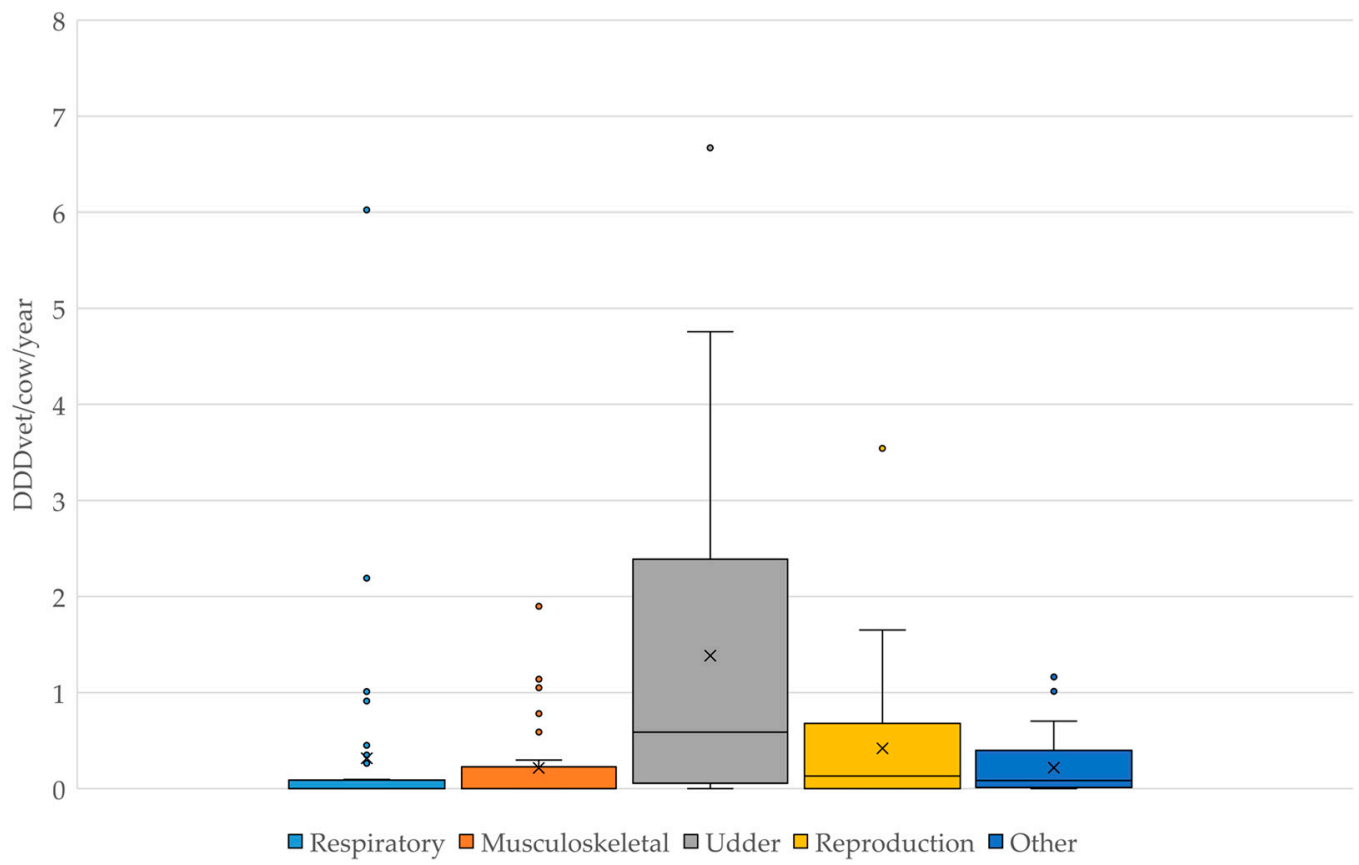

(B)

Figure 2. (A): Comparison of antimicrobial use in DDDvet/cow/year by disease indication on farms which tested POSITIVE for the presence of ESBL-producing E. coli $(\mathrm{N}=13)$. (B): Comparison of antimicrobial use in DDDvet/cow/year by disease indication on farms which tested NEGATIVE for the presence of ESBL-producing E. coli $(\mathrm{N}=37)$. $\mathrm{X}$-mean; horizontal line-median; box-range between 1st and 3rd quartile; dots-outliers.

Dry cow therapy was analysed by Defined Course Dose (DCDvet) per cow and year and is shown in Figure 3. Among farms where at least one sample tested positive for the presence of ESBL-producing E. coli, the median was 0.53 DCDvet/cow/year (mean 0.71), whereas on negative farms the median was $0.50 \mathrm{DCDvet} / \mathrm{cow} /$ year (mean 0.77). 


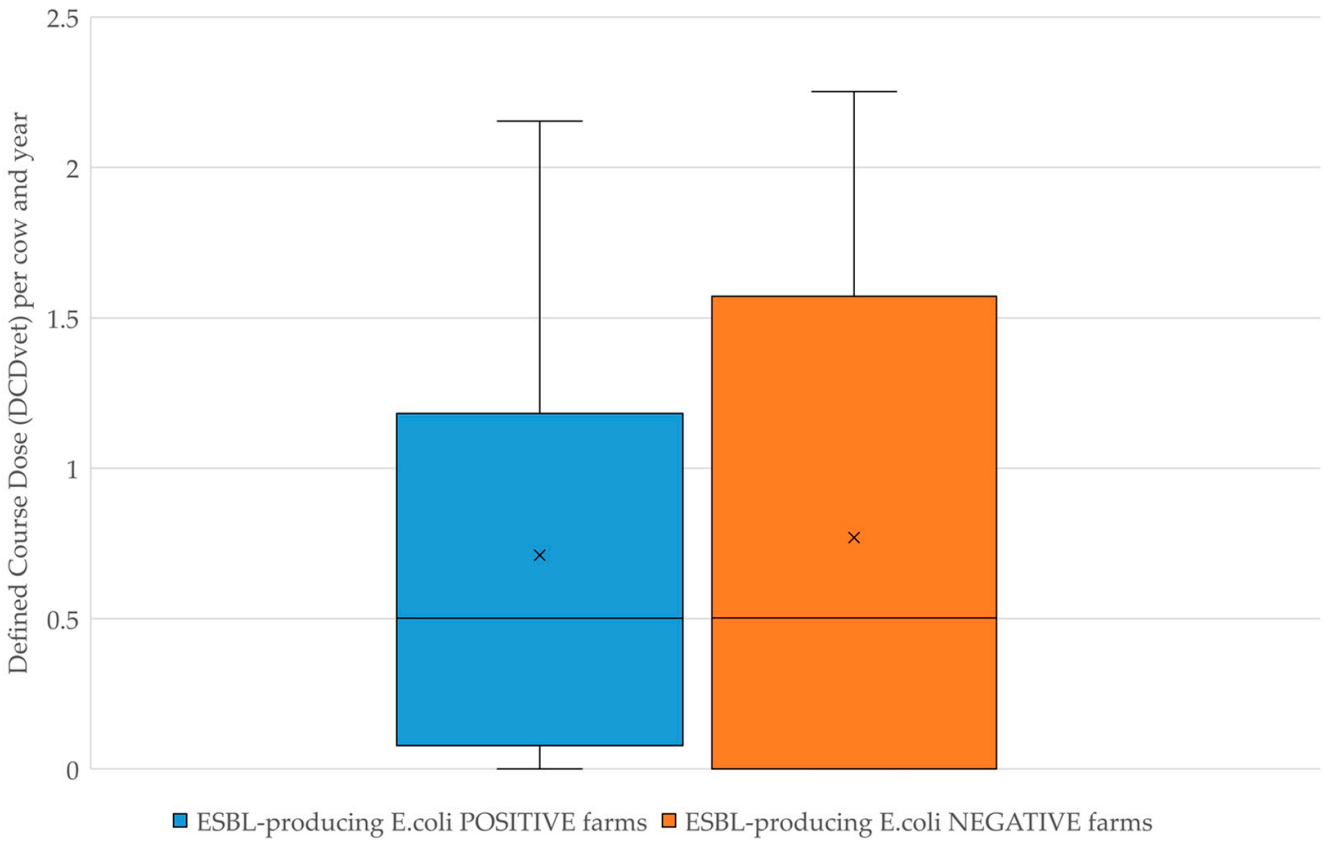

Figure 3. Comparison of antimicrobial dry cow therapy in Defined Course Dose per cow and year (DCDvet/cow/year).

\subsection{Statistical Analysis}

Using the Mann-Whitney U-test for independent samples, no statistically significant difference was determined between AMU in DDDvet/cow/year on each of the farms which were classified as ESBL-producing E. coli positive or negative (Mann-Whitney U score 187.0, $\mathrm{Z}$ score 1.17, $p=0.24$ ). With respect to the use of third and fourth generation cephalosporins, the Mann-Whitney U-test similarly showed no statistically significant difference between the levels of use of this antimicrobial group regardless of whether ESBL-producing E. coli were isolated on the farm or not (Mann-Whitney U score 206.5, $\mathrm{Z}$ score $0.74, p=0.46)$.

Using the Chi-squared test, no statistical significance was found at the $5 \%$ level between ESBL-positive E. coli or negative farms with respect to either "high" $(\geq 2.47 \mathrm{DDDvet} / \mathrm{cow} /$ year) or "low" ( $\leq 0.63 \mathrm{DDDvet} / \mathrm{cow} /$ year) use groups ( $p=0.33)$, or the number of dairy cows $(p=0.42)$ (Tables 3 and 4 ).

Table 3. $2 \times 2$ contingency table with respect to high and low AMU. Observed frequencies of ESBL-producing E. coli positive or negative farms (expected frequencies in brackets).

\begin{tabular}{cccc}
\hline & $\begin{array}{c}\text { High AMU Group } \\
\mathbf{2 . 4 7} \text { DDDvet/Cow/Year }\end{array}$ & $\begin{array}{c}\text { Low AMU Group } \\
\leq \mathbf{0 . 6 3} \text { DDDvet/Cow/Year }\end{array}$ & Total \\
\hline ESBL-producing E. coli-positive & $5(6.5)$ & $8(6.5)$ & 13 \\
ESBL-producing E. coli-negative & $20(18.5)$ & $17(18.5)$ & 37 \\
Total & 25 & 25 & 50 \\
\hline
\end{tabular}

Chi-squared test statistic $0.93, p=0.33$.

Table $4.2 \times 2$ contingency table with respect to numbers of dairy cows. Observed frequencies of ESBL-producing E. coli positive or negative farms (expected frequencies in brackets).

\begin{tabular}{cccc}
\hline & $\leq \mathbf{2 0}$ Dairy Cows & >20 Dairy Cows & Total \\
\hline ESBL-producing E. coli-positive & $5(6.2)$ & $8(6.8)$ & 13 \\
ESBL-producing E. coli-negative & $19(17.8)$ & $18(19.2)$ & 37 \\
Total & 24 & 26 & 50 \\
\hline
\end{tabular}

Chi-squared test statistic $0.64, p=0.42$. 
With respect to feeding calves waste milk, no statistically significant difference was determined for the presence of ESBL-producing E. coli between those farms routinely feeding calves waste milk containing antimicrobial residues and those which did not (Fisher's exact test, $p=0.44$ ) (Table 5).

Table 5. $2 \times 2$ contingency table with respect to whether calves were fed waste milk containing antimicrobial residues on the farm. Observed frequencies of ESBL-producing E. coli positive (at least one positive sample) or negative farms.

\begin{tabular}{cccc}
\hline & Waste Milk Fed to Calves & $\begin{array}{c}\text { Waste Milk NOT Fed } \\
\text { to Calves }\end{array}$ & Total \\
& & 4 & 9 \\
ESBL-producing E. coli-positive & 22 & 9 & 31 \\
ESBL-producing E. coli-negative & 27 & 13 & $40 *$ \\
\hline \multicolumn{2}{c}{ Total } & Fisher's exact test, $p=0.44 .{ }^{*}$ Details on which farms fed waste milk were obtained via a questionnaire, which was
\end{tabular}
completed by $40 / 50$ of the farmers included in this study.

\section{Discussion}

To the authors' knowledge, this is the first study to analyse the presence of antimicrobial-resistant bacteria in relation to antimicrobial use on Austrian dairy farms. The current study represents the first steps in data collection on 50 dairy farms participating in a larger study of 250 farms. Analyses of faecal samples from the farm environment (boot swabs from alleyways of the cowshed, pooled faecal samples from calves and youngstock) determined a low prevalence of ESBL-producing E. coli, with approximately one quarter $(26.0 \%)$ of the 50 farms testing positive in at least one sample. This is relatively low in comparison to neighbouring Bavaria (Germany) where a previous study of dairy and beef farms reported at least one positive ESBL-producing E. coli sample was found on $86.7 \%$ of the 45 farms tested [23]. Similarly, a study in the Netherlands collected ESBL/AmpC-positive samples on $41 \%$ of 100 conventionally run dairy farms [9]. A follow-up to this Dutch study carried out two years later after a change in local legislation to restrict the use of thirdand fourth-generation cephalosporins demonstrated that the herd prevalence between matching herds fell from 32.7\% ESBL/ AmpC E. coli-positive in 2011 to 18.0\% in 2013 [24]. However, the results determined here in Austria are not surprising as they correspond to the most recent official statistics published by the European Food Safety Authority and the European Centre for Disease Prevention and Control in 2020, where 20.5\% of slaughtered calves ( $<1$ year of age) in Austria were found to have presumptive ESBL-producing E. coli in their caeca, compared to a similar prevalence in Switzerland (19.1\%), slightly higher in the Netherlands (36.4\%), and much higher prevalences in Germany $(66.8 \%)$, Belgium $(64.8 \%)$, and Italy $(86.8 \%)$ [25].

The statistical analysis presented here demonstrated that there was no statistically significant correlation between farms classified as "high" ( $\geq 2.47$ DDDvet/cow/year) antimicrobial users or "low" ( $\leq 0.63$ DDDvet/cow/year) antimicrobial users in this study population and the presence of ESBL-producing E. coli on these farms. This trend has also been reported in the Netherlands, where researchers found that the total annual animaldefined daily dose (DDDA) did not significantly differ between ESBL/AmpC-positive and negative farms $[9,26]$. Furthermore, the results presented here did not show a relationship between the presence of ESBL-producing E. coli and the use of third and fourth generation cephalosporins, contrasting with a Dutch study which found the use of these highest priority critically important antimicrobials (HPCIAs) led to an 8.05-fold increase in the odds of testing positive for ESBL/AmpC-producing E. coli [9]. A German study comparing dairy farms, which either did or did not use antimicrobials for a one-year period prior to sampling, found that $30 \%$ of the 10 control farms (no antimicrobial use) were ESBLproducing E. coli positive, while 39/45 (86.7\%) of the dairy farms using antimicrobials tested positive [23]. A recent pan-European analysis on the prevalence of ESBL and/or AmpC-producing E. coli in slaughtered veal calves aged under one year (as well as broilers, 
turkeys, and fattening pigs) has also shown a statistically significant association between the national consumption of third and fourth generation cephalosporins in food-producing animals and the presence of these AMR bacteria (logistic regression based on national data from 31 countries, including Austria, in 2017-2018, odds ratio 1.29 (95\% CI: 1.14; 1.46), $p<0.001)$ [18].

A study in France demonstrated that young calves ( $<7$ weeks of age) on dairy farms were harbouring a variety of AMR bacteria in their intestinal microbiome [27]. In particular, this study demonstrated that the proportion of ESBL-producing E. coli as determined by selective media, fell slightly from $22 \%$ at 15 days of age to $19 \%$ at 7 weeks [27]; a trend which has been observed in many other studies of the intestinal flora of dairy calves [28-31]. While the feeding of waste milk containing antimicrobial residues to calves did not appear to have a statistically significant effect on the farms sampled in the current study, a number of other studies have shown that feeding such milk to calves leads to a transient increase in the presence of AMR bacteria in their faeces [31-34]. It is important to note that, similar to a Canadian study investigating extended-spectrum cephalosporin-resistant $E$. coli in calf faeces [34], the survey of farm management practices in the current study only provided "herd level" information and did not confirm that the calves sampled here had actually received waste milk containing antimicrobial residues, only that it was a routine practice on that farm. Furthermore, we did not investigate the impact of the prevalence of AMR bacteria on this practice.

Although data on MRSA on dairy farms are limited, other European studies in dairy cattle have reported a much higher prevalence of MRSA than that determined in the present study, where only one farm tested positive. A German study of three dairy herds more than a decade ago found that $46.7 \%$ (7/15) of cows tested were MRSA-positive and at a similar time, a Belgian study reported $9.3 \%$ of the 118 dairy farms tested were MRSApositive $[35,36]$. The results determined for MRSA on these 50 Austrian farms are, however, comparable to the extremely low proportion of cattle testing positive for MRSA in a study of patients at the University of Veterinary Medicine in Vienna's ruminant clinic, where only $0.45 \%$ (95\% CI: $0.01 ; 2.90 \%)$ of 221 cattle were MRSA-positive [37].

A previous study of human patients in the federal state of Upper Austria reported that $16 / 21(76.2 \%)$ patients testing positive for MRSA CC398 were either pig or poultry farmers or had relatives with direct animal contact [38]. The Austrian researchers authoring that study suggested that the high level of doxycycline resistance $(19 / 21,90.5 \%)$ of MRSA isolates determined among these MRSA-positive patients could be connected to the relatively high proportion of tetracycline use on pig and poultry farms in Austria at this time [38]. However, a more recent Austrian study reported that human patients were much more likely to become infected with resistant $S$. aureus just through living in rural areas rather than working directly in animal production (OR 1.53 (95\% CI: 1.02; 2.30) vs. OR 0.54 (95\% CI: $0.19 ; 1.55)$ ), although this may have been due to the relatively small number of livestock farmers $(96 / 3309 ; 2.9 \%)$ included in that study population [39].

A study from the United States reported that, of 18 dairy farms sampled, 50\% were positive for antimicrobial-resistant Enterobacteriaceae in environmental sampling and that on three (17\%) of these farms such strains were isolated from 75.1 to $100 \%$ of all tested surfaces [40]. This study found that over $60 \%$ of "shared human and animal contact surfaces" were positive for AmpC and over 20\% were positive for ESBL-producing Enterobacteriaceae, a finding which is extremely relevant for the possible transfer of antimicrobial resistance from animals to humans [40].

A meta-analysis of 181 studies to assess possible associations between antimicrobial use in food-producing animals and antimicrobial resistance in such animals and humans was published in 2017 [41]. A total of 81 studies on animals and 13 studies on humans were included in the final meta-analysis. In this study, the pooled absolute risk differences when interventions were introduced into livestock farming systems to reduce antimicrobial use led to a 10 to $15 \%$ (range 1-39\%) lower proportion of resistant isolates in these systems compared to the control group, where no interventions were implemented [41]. The authors 
of this meta-analysis reported that there is sufficient evidence to demonstrate that a transfer of AMR bacteria can occur between livestock and farm workers and that this appears to occur less frequently when AMU in animal populations is reduced. However, they also pointed out that farmworkers are also the most commonly investigated group and that the evidence is, therefore, weaker for the general human population [41].

While the milk produced in this study population was not specifically tested for ESBL-producing E. coli, other European studies have investigated the presence of these AMR bacteria in the milk. A German study of bulk tank milk detected ESBL-producing Enterobacteriaceae in $9.5 \%$ of the 866 dairy farms tested [42], while a Swiss study of 100 dairy farms did not determine any ESBL-producing E. coli [43] in saleable milk.

In the present study, no statistically significant relationship could be proven between AMU and AMR on farms. It is important to note, however, that AMU on these Austrian dairy farms was relatively low compared to the dairy industry in other European countries [44-47], as well as the pig and poultry sector as a whole, and it is also unlikely that definitive conclusions can be made based on the small number of samples isolated which tested positive for ESBL-producing E. coli.

The main limitation of the current study was that the study population was not randomised and the data on antimicrobial use in this population of dairy cows cannot, therefore, be extrapolated to the rest of the Austrian dairy cow population. However, given the potentially sensitive nature of collecting diagnosis and antimicrobial treatment data directly from herd veterinarians, as well as the high level of commitment required by both veterinarian and farmer to complete all required study tasks, the decision was made to invite veterinarians to participate (convenience sampling) and that they should, in turn, suggest farmers from their client base to join the study (respondent-driven sampling). The subpopulation of 50 farms included here to investigate AMR bacteria was actually part of a much larger study containing around 250 dairy farms. Over a one-year period, the following data were collated from the 250 farms: AMU, bacteriological milk culturing results, veterinary diagnoses, milk recording results, animal movement data, and many other farm management factors $[20,44]$. While it is true that the enrolment of the 50 farms in the current study does indeed introduce a certain level of bias into the study population, we are of the opinion that this bias was limited as neither the farmers nor their herd vets knew which farms would be sampled for AMR bacteria at enrolment. The larger observational study commenced in October 2015, the faecal/dust samples included here were taken in July 2017, and the farms included in the current study were based on their AMU in 2015-2016. We do not believe that the herd veterinarians were able to influence the inclusion or exclusion of specific farms with antimicrobial resistance problems as the initial enrolment of farmers took place in winter 2014/2015, i.e., more than two years prior to AMR samples being collected.

A further limitation may have been the decision to include only the highest and lowest AMU farms in one geographical region in the subpopulation. In theory, the low use farms would have had either no or a low level of selection pressure on the bacteria present leading to a lower probability of resistant bacteria being favoured in the farm environment. In contrast, the high use farms could have had such a broad use of antimicrobials such that even ESBL-producing E. coli were not able to thrive. Nevertheless, we do not believe either of these cases to be true, as we determined no statistically significant difference between the prevalence of ESBL-producing E. coli on high or low AMU farms in this study, and the overall AMU on Austrian dairy farms is known to be relatively low (even the maximum use of antimicrobials on the highest using farm was $<8.10$ DDD/cow/year (median 3.82 DDD/cow/year), compared to other countries [44,45,47-49]).

\section{Materials and Methods}

\subsection{Study Population}

The sample of farms included in this pilot study was taken from a larger nationwide study of 248 Austrian dairy farms, as described elsewhere [20,44]. Overall antimicrobial 
use (AMU) was analysed as part of the previous study [44] and a subset of 50 farms in the federal state of Styria were chosen to participate in this pilot study based on their total AMU over a one-year period. These farms were selected to include the 25 highest users of all AMU and the 25 lowest users in the federal state who were participating in the larger study. The analysis of AMU was based on the Defined Daily Dose metric (DDDvet) as assigned for each antimicrobial active ingredient by the European Medicines Agency [21].

Farms were selected solely on their AMU calculated in DDDvet per cow per year in the previous year, no adjustments were made for housing system, production system (organic or conventional), herd size, or any other farm-related factors.

Bacteriological culture results from milk samples taken from these farms over the one-year study period were available, as described in detail for all 248 farms elsewhere [50]. The most common mastitis pathogens in the larger study population were Staphylococcus spp. (40.1\%), Streptococcus spp. (24.1\%), and Enterobacteriaceae (13.3\%) [50]. A total of 3020 quarter samples from 647 cows on 166 farms were analysed as part of the wider study and it was determined that multiresistant (MDR, i.e., resistant to at least 3 antimicrobials from different classes [51]) strains were most common among Enterobacteriaceae spp., with $14.3 \%(19 / 133)$ of isolates, followed by Staphylococcus spp. with 5.5\% (22/402) MDR isolates [50].

\subsection{Background Information on Udder Health and Herd Management}

Detailed information on the farms included in this pilot study is available in the form of questionnaire responses (see Supplementary Materials), as previously described with respect to mastitis risk factors and overall farm management [20].

\subsection{Total Antimicrobial Use in Defined Daily Dose (DDDvet/Cow/Year)}

Total AMU was calculated from veterinary treatment records covering 1 October 2015 to 30 September 2016, as detailed elsewhere [44,52]. A total of 11 veterinary practices provided data for this pilot study of 50 farms. Briefly, the number of DDDvet were calculated for each antimicrobial substance by dividing the total amount of active substance in milligrams by the European Medicines Agency's predefined DDDvet values [21].

Intramammary treatments were calculated slightly differently, as the European Medicines Agency classes each udder tube as 1 DDDvet, regardless of milligrams of active substance or standardised cow live weight (for details, see [21,44]).

DDDvet values have not been assigned by the EMA for dry cow therapy (DCT) intramammary tubes, only Defined Course Doses (DCDvet). For this reason, DCT was excluded from the majority of the AMU analyses included here. However, as dry cow therapy is an important part of the antimicrobial use statistics of dairy farms, a comparison of the corrected DCDvet/cow/year was carried out between those farms testing positive for the presence of ESBL-producing E. coli and those testing negative. The DCD/cow/year value was corrected by the replacement rate and calving interval for each of the farms included here, as described elsewhere [53].

No antimicrobial treatments were excluded in the present study (with the exception of unquantifiable sprays), regardless of diagnosis.

\subsection{Farm Sampling and Bacteriological Culture}

Each farm was sampled by one of two authors (CLF and WO). Personal protective equipment (PPE) in the form of disposable overalls, gloves, and boot covers were used to ensure that each site was not contaminated. As many Austrian dairy farms keep dualpurpose Simmental cows (Austrian Fleckvieh) for milk production, they frequently rear a number of female replacement heifers, as well as some male animals for beef production. For this reason, cows, calves, and youngstock are often found in the same building or on the same farm.

Each farm was visited in July 2017 and the following samples were collected: 
- 2 pairs of boot swabs either from the alleyways of freestalls where lactating cows were housed or the slurry passage immediately behind cows in tie-stalls

- 1-2 pooled faecal samples from calf pens or freshly voided faeces if calves defaecated while researchers were present (1-5 calves per sample; 2 pooled samples were taken from farms with $>50$ head of cattle)

- 1-2 pooled faecal samples from youngstock (>6 months) pens (if youngstock were present on the farm, 1-5 head per sample; 2 pooled samples were taken from farms with $>50$ head of cattle)

Additionally, one dust sample was collected on dry gauze from 3 to 5 faeces-free areas of the main cowshed (for the isolation of MRSA).

Samples were immediately stored in an insulated cool box until they could be refrigerated. Faecal samples were transported to the laboratory of the Styrian Provincial Government Veterinary Authorities in Graz. Approximately $2 \mathrm{~g}$ faeces from each sample were pre-enriched in $200 \mathrm{~mL}$ buffered peptone water (BPW) at $37{ }^{\circ} \mathrm{C}$ for $18-24 \mathrm{~h}$ and then subsequent selective plated on ChromID-ESBL agar (bioMerieux, Marcy-L'Etoile, France). Plates were incubated at $37^{\circ} \mathrm{C}$ for $24-28 \mathrm{~h}$. Broth microdilution of the presumptive ESBL-producing E. coli was performed using the Sensititre ${ }^{\mathrm{TM}}$ EU Surveillance ESBL (EUVSEC2) plate (Thermo Fisher Scientific, Waltham, MA, USA) according to the manufacturer's instructions (briefly, each well was filled with $50 \mu \mathrm{L}$ inoculum, the plate was then sealed and incubated at $34-36{ }^{\circ} \mathrm{C}$ for $18 \mathrm{~h}$ in a non-CO2 incubator). The Sensititre ${ }^{\mathrm{TM}} \mathrm{EU}$ Surveillance ESBL (EUVSEC2) plate includes wells containing cefotaxime and ceftazidime with or without clavulanic acid, as well as cefoxitin, ertapenem, imipenem, meropenem, cefipime, temocillin, and positive control wells. An ESBL phenotype was categorised according to the EFSA/ECDC standard EU surveillance method, namely a minimal inhibitory concentration (MIC) $>1 \mathrm{mg} / \mathrm{L}$ for cefotaxime and/or ceftazidime, a positive synergy test for these antimicrobials with clavulanic acid, an MIC $\leq 8 \mathrm{mg} / \mathrm{L}$ for cefoxitin, and an $\mathrm{MIC} \leq 0.12 \mathrm{mg} / \mathrm{L}$ for meropenem [54].

Dust samples for MRSA isolation were transported to the National Reference Laboratory for Antimicrobial Resistance at the Institute for Medical Microbiology \& Hygiene, Graz (part of the Austrian Agency for Health and Food Safety (AGES)). Swabs were inoculated in $100 \mathrm{~mL}$ Mueller-Hinton broth supplemented with $6.5 \%$ sodium chloride $(\mathrm{NaCl})$ and incubated for $16-20 \mathrm{~h}$ at $37^{\circ} \mathrm{C}$. A $10 \mu \mathrm{L}$ loopful of pre-enrichment broth was spread on chromID MRSA agar (bioMerieux, Marcy-L'Etoile, France) and incubated for 24-48 h at $37^{\circ} \mathrm{C}$. In addition, $1 \mathrm{~mL}$ of pre-enrichment broth was added to $9 \mathrm{~mL}$ tryptone soya broth (TSB) containing $3.5 \mathrm{mg} / \mathrm{L}$ cefoxitin and $75 \mathrm{mg} / \mathrm{L}$ aztreonam and incubated for another $16-20 \mathrm{~h}$ at $37^{\circ} \mathrm{C}$. A total of $10 \mu \mathrm{L}$ of the selective enrichment broth were spread on chromID MRSA agar (bioMerieux) and incubated for $24-48 \mathrm{~h}$ at $37^{\circ} \mathrm{C}$. Presumptive MRSA colonies were confirmed by Time of Flight Mass Spectrometry (MALDI-TOF MS) and subsequent PCR targeting mecA and mecC according to methods described elsewhere [55,56], with minor deviations (for details, see the Supplementary Materials).

\subsection{Statistical Analysis}

Statistical analyses were carried out using the SPSS (IBM, Armonk, NY, USA) statistical software and Microsoft Excel (Microsoft Corporation, WA, USA). A non-parametric test of independent samples, the Mann-Whitney U-test, was done using the total DDDvet/cow / year for each of the 50 farms and whether at least one sample from the farm tested positive for the presence of ESBL-producing E. coli. This test was then repeated using the DDDvet/cow/year for third and fourth generation cephalosporins for each farm. Furthermore, using $2 \times 2$ contingency tables, the Chi-squared test was carried out on group sizes larger than five, while contingency tables where one or more category was smaller than five were assessed using Fisher's $t$-test. Statistical significance was set at $p<0.05$ in all cases. 


\section{Conclusions}

The level of antimicrobial resistance on the study farms was assessed by means of environmental samples collected from 50 dairy farms in the Austrian federal state of Styria chosen for either their high or low levels of overall AMU over a one-year period. The most frequent indication for antimicrobial use was the treatment of udder disease. No statistically significant relationships between high AMU in DDDvet/cow/year and the presence of these AMR bacteria were determined. While the low prevalence of ESBL-producing $E$. coli in cattle determined here correspond with national AMR monitoring of young calves, our findings may also have been due to the generally low level of antimicrobial use and subsequent lack of selection pressure for resistance genes on the study farms and, therefore, further investigation is needed with a larger sample size.

Supplementary Materials: The following supporting information can be downloaded at: https: / / www.mdpi.com/article/10.3390/antibiotics11020124/s1, S1: English summary of the farm management questionnaire; S2: Description of PCR methods.

Author Contributions: Conceptualisation, C.L.F. and W.O.; methodology, C.L.F., A.K., P.P., S.K.-J. and W.O.; formal analysis, C.L.F. and W.O.; investigation, C.L.F., P.P., S.K.-J. and W.O.; resources, A.K.; data curation, C.L.F. and W.O.; writing-original draft preparation, C.L.F.; writing-review and editing, C.L.F., A.K., P.P., S.K.-J. and W.O.; supervision, W.O. and A.K.; project administration, W.O. and A.K.; funding acquisition, W.O. All authors have read and agreed to the published version of the manuscript.

Funding: The K-Projekt ADDA—Advancement of Dairying in Austria was supported by the Austrian Ministry for Transport, Innovation and Technology (BMVIT), the Federal Ministry of Science, Research and Economy (BMWFJ), the province of Lower Austria and the city of Vienna within the framework of COMET-Competence Centers for Excellent Technologies. The COMET program is handled by the Austrian Research Promotion Agency (FFG). C.L.F. is partly funded by the K-Project "D4Dairy" which is supported by BMVIT, BMDW, the province of Lower Austria and the city of Vienna.

Institutional Review Board Statement: In accordance with national legislation and good scientific practice (GSP) guidelines, the study was registered with the institutional ethics and animal welfare committee of the University of Veterinary Medicine, Vienna (Ref No. ETK-13/11/2015). No invasive procedures were performed as part of this study.

Informed Consent Statement: Written informed consent was obtained from all farmers and veterinarians involved in the study.

Data Availability Statement: The authors do not own the antimicrobial use data analysed here. These data were collected from the veterinarians who were treating the animals included in the study. Under the data privacy agreement signed by the farmers and veterinarians, these data are not available to be published.

Acknowledgments: The authors would like to thank all the veterinarians and farmers who participated in this study, and Stefanie Klatovsky for help with PCR amplification of mecA/mecC.

Conflicts of Interest: The authors declare no conflict of interest. The funders had no role in the design of the study; in the collection, analyses, or interpretation of data; in the writing of the manuscript, or in the decision to publish the results.

\section{References}

1. O'Neill, J. Antimicrobials in Agriculture and the Environment: Reducing Unnecessary Use and Waste; HM Government: London, UK, 2015.

2. Tiseo, K.; Huber, L.; Gilbert, M.; Robinson, T.P.; Boeckel, T.P. Van Global Trends in Antimicrobial Use in Food Animals from 2017 to 2030. Antibiotics 2020, 9, 918. [CrossRef]

3. Maron, D.F.; Smith, T.J.S.; Nachman, K.E. Restrictions on antimicrobial use in food animal production: An international regulatory and economic survey. Global. Health 2013, 9, 1-11. [CrossRef]

4. European Medicines Agency. Sales of Veterinary Antimicrobial agents in 31 European Countries in 2019 and 2020 (11th ESVAC Report); 2021. Available online: https:/ /www.ema.europa.eu/en/documents/report/sales-veterinary-antimicrobial-agents31-european-countries-2019-2020-trends-2010-2020-eleventh_en.pdf (accessed on 23 December 2021). 
5. BMG Verordnung des Bundesministers für Gesundheit, mit der ein System zur Überwachung des Vetriebs und Verbrauchs von Antibiotika im Veterinärbereich eingereicht wird (Veterinär-Antibiotika-Mengenströme-VO) sowie die Verordnung über die Einrichtung und Führung der Tierärzteliste. Available online: https://www.ris.bka.gv.at/Dokumente/BgblAuth/BGBLA_2014 _II_83/BGBLA_2014_II_83.pdf (accessed on 1 June 2017).

6. Fuchs, R.; Fuchs, K. Bericht über den Vertrieb von Antibiotika in der Veterinärmedizin in Österreich $2016-2020$ (Report on Veterinary Antimicrobial Sales/Dispensing in Austria 2016-2020); Graz, Austria, 2021. Available online: https: //www.ages.at/download/0/0/f290c2127644b5369881327c484607518e526e66/fileadmin/AGES2015/Themen/AGES_ Schwerpunktthemen/Antibiotika/AB_Mengen_AUT_Bericht_2020.pdf (accessed on 22 December 2021).

7. Chantziaras, I.; Boyen, F.; Callens, B.; Dewulf, J. Correlation between veterinary antimicrobial use and antimicrobial resistance in food-producing animals: A report on seven countries. J. Antimicrob. Chemother. 2014, 69, 827-834. [CrossRef]

8. Albrich, W.C.; Monnet, D.L.; Harbarth, S. Antibiotic Selection Pressure and Resistance in Streptococcus pneumoniae and Streptococcus pyogenes-Volume 10, Number 3-March 2004-Emerging Infectious Diseases journal-CDC. Emerg. Infect. Dis. 2004, 10, 514-517. [CrossRef]

9. Gonggrijp, M.A.; Santman-Berends, I.M.G.A.; Heuvelink, A.E.; Buter, G.J.; van Schaik, G.; Hage, J.J.; Lam, T.J.G.M. Prevalence and risk factors for extended-spectrum $\beta$-lactamase- and AmpC-producing Escherichia coli in dairy farms. J. Dairy Sci. 2016, 99, 9001-9013. [CrossRef] [PubMed]

10. Sjöström, K.; Hickman, R.A.; Tepper, V.; Antillón, G.O.; Järhult, J.D.; Emanuelson, U.; Fall, N.; Lewerin, S.S. Antimicrobial Resistance Patterns in Organic and Conventional Dairy Herds in Sweden. Antibiotics 2020, 9, 834. [CrossRef] [PubMed]

11. Irrgang, A.; Roschanski, N.; Tenhagen, B.-A.; Grobbel, M.; Skladnikiewicz-Ziemer, T.; Thomas, K.; Roesler, U.; Käsbohrer, A Prevalence of mcr-1 in E. coli from Livestock and Food in Germany, 2010-2015. PLoS ONE 2016, 11, e0159863. [CrossRef]

12. Roschanski, N.; Guenther, S.; Vu, T.T.T.; Fischer, J.; Semmler, T.; Huehn, S.; Alter, T.; Roesler, U. VIM-1 carbapenemase-producing Escherichia coli isolated from retail seafood, Germany 2016. Eurosurveillance 2017, 22, 17-00032. [CrossRef]

13. George, A. Antimicrobial resistance, trade, food safety and security (Editorial Commentary). One Health 2018, 5, 6-8. [CrossRef] [PubMed]

14. Petternel, C.; Galler, H.; Zarfel, G.; Luxner, J.; Haas, D.; Grisold, A.J.; Reinthaler, F.F.; Feierl, G. Isolation and characterization of multidrug-resistant bacteria from minced meat in Austria. Food Microbiol. 2014, 44, 41-46. [CrossRef]

15. Much, P.; Sun, H. Bericht zur AntibiotikaresistenzÜberwachung gemäß Durchführungsbeschluss der Kommission 2013/652/EU in Österreich, 2019. In Resistenzbericht Österreich AURES 2019; Bundesministerium für Soziales, Gesundheit, Pflege und Konsumentenschutz (BMSGPK): Vienna, Austria, 2021; pp. 357-394.

16. EFSA/ECDC. Annex E-Data on presumptive ESBL-, AmpC- and/or carbapenemase- producing microorganisms and their resistance occurrence (routine and specific monitoring). EFSA J. 2021, 19, 2015-2019. [CrossRef]

17. EFSA/ECDC. Annex F-Data reported on antimicrobial resistance in MRSA from food-producing animals and derived meat. EFSA J. 2021, 19, 1-17. [CrossRef]

18. ECDC; EFSA; EMA. Antimicrobial Consumption and Resistance in Bacteria from Humans and Animals Third Joint Inter-Agency Report on Integrated Analysis of Antimicrobial agent Consumption and Occurrence of Antimicrobial Resistance in Bacteria from Humans and Food-Producing an. Available online: https://www.ecdc.europa.eu/sites/default/files/documents/JIACRA-IIIAntimicrobial-Consumption-and-Resistance-in-Bacteria-from-Humans-and-Animals.pdf (accessed on 24 November 2021).

19. Mughini-Gras, L.; Dorado-García, A.; van Duijkeren, E.; van den Bunt, G.; Dierikx, C.M.; Bonten, M.J.M.; Bootsma, M.C.J.; Schmitt, H.; Hald, T.; Evers, E.G.; et al. Attributable sources of community-acquired carriage of Escherichia coli containing $\beta$-lactam antibiotic resistance genes: A population-based modelling study. Lancet Planet. Heal. 2019, 3, e357-e369. [CrossRef]

20. Firth, C.L.; Laubichler, C.; Schleicher, C.; Fuchs, K.; Käsbohrer, A.; Egger-Danner, C.; Köfer, J.; Obritzhauser, W. Relationship between the probability of veterinary-diagnosed bovine mastitis occurring and farm management risk factors on small dairy farms in Austria. J. Dairy Sci. 2019, 102, 4452-4463. [CrossRef]

21. EMA Defined Daily Doses for Animals (DDDvet) and Defined Course Doses for Animals (DCDvet): European Surveillance of Veterinary Antimicrobial Consumption (ESVAC). Available online: http://www.ema.europa.eu/docs/en_GB/document_ library/Other/2016/04/WC500205410.pdf (accessed on 1 July 2021).

22. WHO. Critically Important Antimicrobials for Human Medicine- 5th Revision 2016; Cambridge University Press: Geneva, Switzerland, 2017.

23. Schmid, A.; Hörmansdorfer, S.; Messelhäusser, U.; Käsbohrer, A.; Sauter-Louis, C.; Mansfeld, R. Prevalence of extended-spectrum beta-lactamase-producing Escherichia coli on Bavarian dairy and beef cattle farms. Appl. Environ. Microbiol. 2013, 79, 3027-3032. [CrossRef]

24. Heuvelink, A.E.; Gonggrijp, M.A.; Buter, R.G.J.; ter Bogt-Kappert, C.C.; van Schaik, G.; Velthuis, A.G.J.; Lam, T.J.G.M. Prevalence of extended-spectrum and AmpC $\beta$-lactamase-producing Escherichia coli in Dutch dairy herds. Vet. Microbiol. 2019, $232,58-64$. [CrossRef]

25. EFSA/ECDC. The European Union Summary Report on Antimicrobial Resistance in zoonotic and indicator bacteria from humans, animals and food in 2017/2018. EFSA J. 2020, 18, e06007. [CrossRef]

26. Santman-Berends, I.M.G.A.; Gonggrijp, M.A.; Hage, J.J.; Heuvelink, A.E.; Velthuis, A.; Lam, T.J.G.M.; van Schaik, G. Prevalence and risk factors for extended-spectrum $\beta$-lactamase or AmpC-producing Escherichia coli in organic dairy herds in the Netherlands. J. Dairy Sci. 2017, 100, 562-571. [CrossRef] [PubMed] 
27. Jarrige, N.; Cazeau, G.; Bosquet, G.; Bastien, J.; Benoit, F.; Gay, E. Effects of antimicrobial exposure on the antimicrobial resistance of Escherichia coli in the digestive flora of dairy calves. Prev. Vet. Med. 2020, 185, 105177. [CrossRef] [PubMed]

28. Pereira, R.V.V.; Siler, J.D.; Bicalho, R.C.; Warnick, L.D. In Vivo Selection of Resistant E. coli after Ingestion of Milk with Added Drug Residues. PLoS ONE 2014, 9, e115223. [CrossRef]

29. Pereira, R.V.V.; Carroll, L.M.; Lima, S.; Foditsch, C.; Siler, J.D.; Bicalho, R.C.; Warnick, L.D. Impacts of feeding preweaned calves milk containing drug residues on the functional profile of the fecal microbiota. Sci. Rep. 2018, 8, 554. [CrossRef]

30. EFSA Panel on Biological Hazards; Ricci, A.; Allende, A.; Bolton, D.; Chemaly, M.; Davies, R.; Fernández Escámez, P.S.; Girones, R.; Koutsoumanis, K.; Lindqvist, R.; et al. Risk for the development of Antimicrobial Resistance (AMR) due to feeding of calves with milk containing residues of antibiotics. EFSA J. 2017, 15, e04665. [CrossRef]

31. Firth, C.L.; Kremer, K.; Werner, T.; Käsbohrer, A. The Effects of Feeding Waste Milk Containing Antimicrobial Residues on Dairy Calf Health. Pathogens 2021, 10, 112. [CrossRef] [PubMed]

32. Horton, R.A.; Duncan, D.; Randall, L.P.; Chappell, S.; Brunton, L.A.; Warner, R.; Coldham, N.G.; Teale, C.J. Longitudinal study of CTX-M ESBL-producing E. coli strains on a UK dairy farm. Res. Vet. Sci. 2016, 109, 107-113. [CrossRef] [PubMed]

33. Maynou, G.; Terré, M.; Bach, A.; Chester-Jones, H.; Migura-Garcia, L.; Ziegler, D. Effects of feeding pasteurized waste milk to dairy calves on phenotypes and genotypes of antimicrobial resistance in fecal Escherichia coli isolates before and after weaning. $J$. Dairy Sci. 2017, 100, 7967-7979. [CrossRef] [PubMed]

34. Awosile, B.; McClure, J.; Sanchez, J.; Rodriguez-Lecompte, J.C.; Keefe, G.; Heider, L.C. Salmonella enterica and extended-spectrum cephalosporin-resistant Escherichia coli recovered from Holstein dairy calves from 8 farms in New Brunswick, Canada. J. Dairy Sci. 2018, 101, 3271-3284. [CrossRef] [PubMed]

35. Vanderhaeghen, W.; Cerpentier, T.; Adriaensen, C.; Vicca, J.; Hermans, K.; Butaye, P. Methicillin-resistant Staphylococcus aureus (MRSA) ST398 associated with clinical and subclinical mastitis in Belgian cows. Vet. Microbiol. 2010, 144, 166-171. [CrossRef]

36. Spohr, M.; Rau, J.; Friedrich, A.; Klittich, G.; Fetsch, A.; Guerra, B.; Hammerl, J.A.; Tenhagen, B.A. Methicillin-resistant Staphylococcus aureus (MRSA) in three dairy herds in southwest Germany. Zoonoses Public Health 2011, 58, 252-261. [CrossRef]

37. Schauer, B.; Krametter-Frötscher, R.; Knauer, F.; Ehricht, R.; Monecke, S.; Feßler, A.T.; Schwarz, S.; Grunert, T.; Spergser, J.; Loncaric, I. Diversity of methicillin-resistant Staphylococcus aureus (MRSA) isolated from Austrian ruminants and New World camelids. Vet. Microbiol. 2018, 215, 77-82. [CrossRef]

38. Krziwanek, K.; Metz-Gercek, S.; Mittermayer, H. Methicillin-resistant staphylococcus aureus ST398 from human patients, Upper Austria. Emerg. Infect. Dis. 2009, 15, 766-769. [CrossRef] [PubMed]

39. Hoffmann, K.; den Heijer, C.D.J.; George, A.; Apfalter, P.; Maier, M. Prevalence and resistance patterns of commensal S. aureus in community-dwelling GP patients and socio-demographic associations: A cross-sectional study in the framework of the APRES-project in Austria. BMC Infect. Dis. 2015, 15, 1-9. [CrossRef]

40. Adams, R.J.; Kim, S.S.; Mollenkopf, D.F.; Mathys, D.A.; Schuenemann, G.M.; Daniels, J.B.; Wittum, T.E. Antimicrobial-resistant Enterobacteriaceae recovered from companion animal and livestock environments. Zoonoses Public Health 2018, 65, 519-527. [CrossRef] [PubMed]

41. Tang, K.L.; Caffrey, N.P.; Nóbrega, D.B.; Cork, S.C.; Ronksley, P.E.; Barkema, H.W.; Polachek, A.J.; Ganshorn, H.; Sharma, N.; Kellner, J.D.; et al. Restricting the use of antibiotics in food-producing animals and its associations with antibiotic resistance in food-producing animals and human beings: A systematic review and meta-analysis. Lancet Planet. Health 2017, 1, e316-e327. [CrossRef]

42. Odenthal, S.; Akineden, Ö.; Usleber, E. Extended-spectrum $\beta$-lactamase producing Enterobacteriaceae in bulk tank milk from German dairy farms. Int. J. Food Microbiol. 2016, 238, 72-78. [CrossRef] [PubMed]

43. Geser, N.; Stephan, R.; Hächler, H. Occurrence and characteristics of extended-spectrum $\beta$-lactamase (ESBL) producing Enterobacteriaceae in food producing animals, minced meat and raw milk. BMC Vet. Res. 2012, 8, 1-9. [CrossRef] [PubMed]

44. Firth, C.L.; Käsbohrer, A.; Schleicher, C.; Fuchs, K.; Egger-Danner, C.; Mayerhofer, M.; Schobesberger, H.; Köfer, J.; Obritzhauser, W Antimicrobial consumption on Austrian dairy farms: An observational study of udder disease treatments based on veterinary medication records. PeerJ 2017, 5, e4072. [CrossRef] [PubMed]

45. Stevens, M.; Piepers, S.; Supré, K.; Dewulf, J.; De Vliegher, S. Quantification of antimicrobial consumption in adult cattle on dairy herds in Flanders, Belgium, and associations with udder health, milk quality, and production performance. J. Dairy Sci. 2016, 99, 2118-2130. [CrossRef] [PubMed]

46. Kuipers, A.; Koops, W.J.; Wemmenhove, H. Antibiotic use in dairy herds in the Netherlands from 2005 to 2012 . J. Dairy Sci. 2016, 99, 1632-1648. [CrossRef]

47. More, S.J.; Clegg, T.A.; McCoy, F. The use of national-level data to describe trends in intramammary antimicrobial usage on Irish dairy farms from 2003 to 2015. J. Dairy Sci. 2017, 100, 1-14. [CrossRef] [PubMed]

48. Pol, M.; Ruegg, P.L. Treatment practices and quantification of antimicrobial drug usage in conventional and organic dairy farms in Wisconsin. J. Dairy Sci. 2007, 90, 249-261. [CrossRef]

49. Saini, V.; McClure, J.T.; Scholl, D.T.; DeVries, T.J.; Barkema, H.W. Herd-level association between antimicrobial use and antimicrobial resistance in bovine mastitis Staphylococcus aureus isolates on Canadian dairy farms. J. Dairy Sci. 2012, 95, 1921-1929. [CrossRef] [PubMed] 
50. Schabauer, A.; Pinior, B.; Gruber, C.-M.; Firth, C.L.; Käsbohrer, A.; Wagner, M.; Rychli, K.; Obritzhauser, W. The relationship between clinical signs and microbiological species, spa type, and antimicrobial resistance in bovine mastitis cases in Austria. Vet. Microbiol. 2018, 227, 52-60. [CrossRef]

51. Magiorakos, A.-P.; Srinivasan, A.; Carey, R.B.; Carmeli, Y.; Falagas, M.E.; Giske, C.G.; Harbarth, S.; Hindler, J.F. Multidrugresistant, Extensively Drug-resistant and Pandrug-resistant Bacteria: An International Expert Proposal for Interim Standard Definitions for Acquired Resistance. Clin. Microbiol. Infect. 2012, 18, 268-281. [CrossRef]

52. Firth, C.L. Analysis of antimicrobial use for the treatment of mastitis and antimicrobial resistance of clinically-relevant and commensal bacterial isolates on dairy farms in Austria, University of Veterinary Medicine Vienna, 2018. Available online: https: / / permalink.obvsg.at/UVW/AC15385467 (accessed on 22 December 2021).

53. Firth, C.L.; Käsbohrer, A.; Egger-Danner, C.; Fuchs, K.; Pinior, B.; Roch, F.F.; Obritzhauser, W. Comparison of defined course doses (DCDvet) for blanket and selective antimicrobial dry cow therapy on conventional and organic farms. Animals 2019, 9, 707. [CrossRef] [PubMed]

54. EFSA/ECDC Annex A-Materials and methods: The European Union Summary Report on Antimicrobial Resistance in zoonotic and indicator bacteria from humans, animals and food in 2018/2019. EFSA J. 2021, 19, 6490. [CrossRef]

55. Murakami, K.; Minamide, W.; Wada, K.; Nakamura, E.; Teraoka, H.; Watanabe, S. Identification of methicillin-resistant strains of staphylococci by polymerase chain reaction. J. Clin. Microbiol. 1991, 29, 2240-2244. [CrossRef]

56. Cuny, C.; Layer, F.; Strommenger, B.; Witte, W. Rare occurrence of methicillin-resistant Staphylococcus aureus CC130 with a novel mecA homologue in humans in Germany. PLoS ONE 2011, 6, e24360. [CrossRef] 